\title{
Expansion Effects Shown by Some Pyrex Glasses
}

\author{
By Arthur Q. Tool and James B. Saunders
}

\begin{abstract}
Thermal expansion data are presented, which apparently confirm a previously expressed belief that some of the borosilicate glasses containing a high percentage of silica are essentially two-component glasses. One of these components is presumably composed almost entirely of silica and forms into a comparatively rigid and continuous spatial network that pervades the whole glass. This formation develops before the glass is cooled into the annealing range of the other component that is composed of a portion of the silica and most of the other constituents. On being cooled into its annealing range and particularly on reaching temperatures below this range, the low-temperature component also forms a fairly rigid network that is interlaced with that of the high-temperature component. The latter, being composed mainly of silica, possesses a considerably lower expansivity than the other. Consequently, the low-temperature component, whenever it behaves as a rigid network, elastically compresses the other component on cooling and is, in turn, elastically distended. Annealing the glass at suitable temperatures relaxes the compressions and distensions. Such relaxations cause expansions and contractions that are unlike those found in a normal single-component glass. As a result, thermal expansion cycles obtained on glasses containing a high percentage of silica show certain peculiarities. Several cases in which these peculiarities appear are presented and discussed.
\end{abstract}

\section{Introduction}

\section{Possibility of Two-Component Glasses}

In previous papers $[1,2,3]^{1}$ attention has been called to certain peculiarities possessed by borosilicate glasses with a rather high silica content, such as is found in some Pyrex glasses. In one of these papers [1], it was pointed out that such glasses behave, while within their annealing ranges, as if they consist of a comparatively rigid framework or cellular structure of large and possibly complex molecules that is surrounded or filled by a component that is still fluid. Thus, the glass at this stage appears to consist of two components or glasses, one that has practically reached the vitreous solid state and another that is still in the highly viscous liquid state. Possibly, most glasses possess this characteristic to a limited extent.

The possibility that borosilicate glasses with high-silica content are in effect composed of twocomponent glasses was first suggested by the

\footnotetext{
1 Figures in brackets indicate the literature references at the end of this paper.
}

double endothermic effect that is observed in some samples of this type of glass when they are heated. This view concerning the nature of these glasses was considerably strengthened when it was found that it could be used to anticipate the consequences that variations in annealing or other heat-treating schedules have in changing the temperature range and magnitude of the endothermic effects of heat-treated samples. By properly regulating the treating schedule, the endothermic effect can be reduced to practically a single effect (as it normally appears in ordinary glasses), or its apparent duality can be accentuated.

\section{Softening Ranges and Probable Compositions of Components}

From a study of the endothermic effects, as exhibited by heating curves obtained on a number of samples that had received different heat treatments, it appears that the more fluid component of some of the glasses tested became a vitreous solid at a temperature that was approximately $100^{\circ} \mathrm{C}$ below that at which the less fluid compo- 
nent reached a stage of comparative rigidity. Roughly speaking, the softening range of the first of these components in ordinary Pyrex glasses extended from somewhat below $500^{\circ}$ to $600^{\circ} \mathrm{C}$, and the other extended from approximately $600^{\circ}$ to $700^{\circ} \mathrm{C}$.

In speaking of glass as consisting of two or more component glasses, there is no intention of suggesting that the constituent molecules are sharply divided among them according to definite categories. More probably, the division of the molecules between the components is somewhat indefinite and subject to some change whenever the glass is treated differently at temperatures within or just above its annealing range. Moreover, some individual molecules or complexes of all categories may form a part of both components. Whenever one constituent is in excess and is also capable of forming a glass of itself, it is likely to predominate in one of the components. In view of the composition, it seems that the predominant constituent of the high-temperature component in ordinary Pyrex glasses is silica. In other words, this component consists, for the most part, of associated complexes of silica molecules and chains, and the other consists of almost all the remaining constituents with an appreciable portion of the silica. Heating curves that exhibit endothermic effects supporting this surmise concerning the constituency of the high-temperature component were shown in another publication [4].

In the investigation reported in reference [4], samples of a Pyrex glass were held for considerable periods at temperatures above $650^{\circ} \mathrm{C}$ to devitrify them. At such temperatures, the low-temperature component is sufficiently mobile to act as an efficient flux that aids in the disintegration of the partially softened high-temperature component and in the formation of cristobalite from it. After the crystallization of the silica is carried as far as possible, the remaining glass no longer shows an endothermic effect corresponding to the hightemperature component. In other words, this component, as a glass, has apparently vanished. Moreover, the remaining endothermic effect is not unlike that of an ordinary borosilicate glass, and it actually occurs in a slightly lower-temperature range than that of the low-temperature component before the other component was removed. This result indicates that the low-temperature component may also have lost some silica as a result of the devitrification. Thus, there is little doubt that silica is also an important constituent of the low-temperature component.

\section{Density and Expansivity of a Two-Component Glass}

Besides causing uncommon variations in the endothermic effects of a glass, the presence of two components with widely different softening ranges affects other phenomena associated with the annealing and disannealing of glasses. Two of these phenomena are the density changes caused by annealing and the extraordinary expansion of glasses in their annealing ranges. Some of the density changes observed as a result of heat treating these supposedly two-component glasses have already been presented [2,3]. Also, preliminary results on the peculiarities of the extraordinary expansions of these glasses were included in a paper [5] read at the Toronto meeting of the American Ceramic Society in 1930.

A more extended set of observations on the extraordinary expansions is the subject of the present paper; but before they are taken up, it should be pointed out that the general nature of the results of the experiments can be anticipated from the implied concepts involved in the hypothesis of a two-component glass, especially if there is sufficient knowledge of the nature of the components. In the case of an ordinary Pyrex glass, it has been presumed that the high-temperature component is predominently silica. Consequently this component, as compared to ordinary glasses of lower silica content, has a low expansivity and a high annealing range in which the extraordinary expansion is probably not outstanding and the density changes resulting from variations in annealing are small. The other component presumably contains most of the remaining constituents of the glass. As a result, the composition of the latter is not unlike that of some ordinary glasses that are normal both in respect to expansivities and annealing ranges and that, after being well annealed, show a considerable increase in density and also a moderately large extraordinary expansion if reheated through the annealing range.

When measured at some standard temperature well below the annealing range, the expansivity of any ordinary glass so far tested always decreases as the equilibrium temperature is decreased, and the maximum change attainable appears to be 
about 10 percent. The same result should also be obtained on a two-component glass, such as that described above, because changes in the effective annealing temperature of the low-temperature component should dominate any expansivity changes of this nature, although the expansivity of the glass as a whole naturally lies between the expansivities of the two components. In other words, it is impossible to produce by annealing treatments any change in the expansivity of the high-temperature component that is not overshadowed by changes of similar origin in the other component. Moreover, because of the dominance of the low-temperature component in this effect, the range of annealing temperatures within which such a decrease in expansivity is producible will approximately coincide with the annealing range of that component (that is, from $450^{\circ}$ to $600^{\circ} \mathrm{C}$, approximately, for an ordinary Pyrex glass). These conclusions are seemingly corroborated by the results obtained in the investigation [3] of the effect of heat treatment on the expansivity of a pyrex glass.

\section{Probable Results of Certain Heat Treat- ments of Two-Component Glasses}

\section{First Type of Glass}

With regard to the extraordinary expansions of two-component glasses, a great variety of results can be obtained by varying the heat treatments. These effects develop not only as the glass is being heated or cooled through the annealing range, but also while it is being held at a constant temperature in that range. Because these effects are closely associated with the endothermic and exothermic effects, which may be observed by heating a glass through its annealing range, and are also related to density changes, the effects of which persist even after a glass is cooled to ordinary temperatures, it is obvious that any peculiarities in the extraordinary expansions will be associated with corresponding peculiarities in the heat effects and density changes. With this picture of the particular two-component glass under consideration, the following conclusions can be reached as to its probable behavior and properties after it is subjected to certain specific heat treatments.

Treatment $(a)$.- The first treatment to be considered is that in which the glass is cooled rapidly to atmospheric temperatures from temperatures that are above the annealing range of the hightemperature component. This treatment corresponds to that received by glass tubing and small or thin articles that, after being drawn, molded, or blown, are cooled in air at atmospheric temperatures and receive no intermediate or later annealing. At high temperatures suitable for drawing and molding, thermal agitation holds the components in a comparatively high degree of disorganization and the rapid cooling allows very little of the organization ${ }^{2}$ that slow cooling and annealing encourage. After being so treated, the glass, on being reheated at a normal rate for testing, will show extraordinary expansions that differ little if any from those shown by a single-component glass treated similarly and having the approximate composition of the low-temperature component. That is, the expansion curve will indicate a small or possibly negative expansion as the annealing range of the low-temperature component is entered, and this effect will be followed by a very large expansion in the upper part of this same annealing range. At higher temperatures, the low-temperature component having fully assumed the characteristics of a liquid glass [6] expands much more rapidly than at temperatures below its annealing range. This increased expansion obliterates any peculiarities that the high-temperature component contributes, in its annealing range, to the expansion curve. Moreover, it is impossible to obtain satisfactory linear-expansion curves in that range because the softening of the low-temperature component has too greatly increased the inelastic deformability of the glass.

Fortunately, the exothermic and endothermic effects that are shown by differential-heating curves, obtained in the usual manner [1], can be observed throughout the annealing ranges of both components. A study of the genesis of these heat

\footnotetext{
2 "Organization" as used here and in the following discussion refers to the development of molecular relationships that may or may not be the same as any of those more-or-less hypothetical relationships that have been proposed by various investigators in discussions of vitreous materials. Examples of the hypothetical molecular structures that have been discussed are the silica, threadlike structure considered by R. B. Sosman in his monograph on "The properties of silica" (Chemical Catalog Co., New York, N. Y., 1927) and the chain or ring-like structures considered by E. Preston (J. Soc. Glass Tech. 26, 82, 1942). Seemingly, such structures should be conducive to the building up of extended networks especially in silica-rich glasses. Other (although not always wholly different) hypotheses concerning extended molecular structures have been advanced in discussions on the constitution of glasses. Some of these hypotheses are mentioned by G. W. Morey in his monograph on "The properties of glass"' (Reinhold Publishing Corp., New York, N. Y., 1938). As some of the proposed structures or networks concern silica glasses containing other constituents, they must be considered as possibilities especially in connection with the low-temperature component.
} 
effects $[6,7]$, and of the conditions probably developed by the heat treatment under consideration, leads to the conclusion that the general appearance of the heating curves obtained in this case will differ little from those that would be obtained on any chilled ordinary single-component glass if it had an unusually broad annealing range. In other words, the curves will indicate that an exothermic effect developed near the lower limit of the annealing range of the low-temperature component, and that the following endothermic effect extended without apparent break over the annealing ranges of both components. Curve 5 in figure 1 presents such indications. Excepting

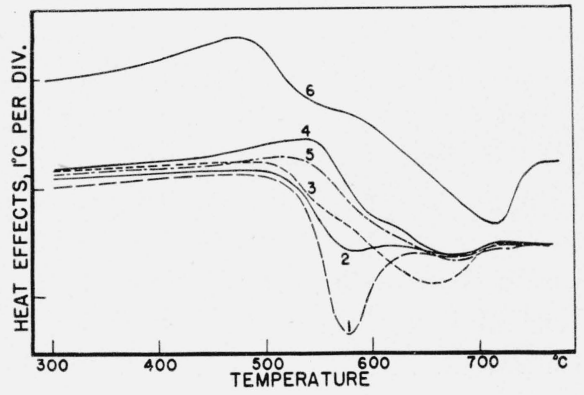

FIGURE 1. Differential heating curves showing exothermic and endothermic effects.

Ordinary Pyrex glass, such as used in ehemical ware: Curve 1, after treatment for 21 days at $450^{\circ} \mathrm{C}$; curve 2 , untreated glass; curve 3 , after treatment for 30 hours at $550^{\circ} \mathrm{C}$; curve 4 , after treatment for 1 hour at $700^{\circ} \mathrm{C}$; curve 5 , after treatment of 1 hour at $850^{\circ} \mathrm{C}$. G702P glass; curve 6 , untreated.

a slight change in curvature just above $600^{\circ} \mathrm{C}$, there is no indication in this curve of an exothermic effect near the beginning of the annealing range of the high-temperature component. As this component was chilled by the treatment imposed on the glass, it should produce an exothermic effect as it anneals near $600^{\circ} \mathrm{C}$ during the heating required by the test. However, such an effect will be comparatively small if the component is constituted mainly of silica. Moreover, such an effect may be practically obliterated because it is overlapped by the endothermic effect of the low-temperature component.

After this type of cooling treatment, which usually follows the production of any small glass article and which in this case allows neither component opportunity to develop molecular reorganization and compaction to the degree normally induced by annealing, the density will be definitely lower than after any annealing treatment that is capable of increasing the general compaction and which thereby appreciably reduces the "unoccupied" or intermolecular space. However, when a glass is composed of two major components with appreciably different properties, it must be expected that the interaction between these components during various heat treatments and especially during rapid coolings or heatings will cause extraordinary variations in the unoccupied space. Hence, this interaction must be taken into account when considering the effects that heat treatments have on density.

During a rapid cooling the behavior of both components, even before they reach their respective annealing ranges, is very much like that of vitreous solids. This likeness increases very rapidly as the temperature decreases and the viscosity increases. In other words, there is comparatively little shifting of the relative positions of the molecules except through the development of elastic molecular strains. Such strains are doubtless compressions of the component with a low expansivity (the high-temperature component in the glasses now under consideration) and distensions of the component with a high expansivity. Release of these strains by annealing in the annealing range of the low-temperature component will modify the compaction (increase in density) normally developed by annealing. The normal density change caused by annealing a chilled glass is an appreciable increase that develops at a decreasing rate as equilibrium is approached at the annealing temperature. In the beginning of an annealing of a chilled two-component glass in the annealing range of the lowtemperature component, the same sort of compaction develops and increases the elastic strains. As these strains increase, their rate of relaxation increases if the viscosity is not too greatly increased by the compaction. As the strains relax, the compressed and comparatively rigid high-temperature component expands the glass. This expansion continues long after the previously ascendant contraction of the low-temperature component is practically ended. That is, a two component glass after being subjected to treatment (a) should first contract and then expand under certain conditions of annealing. Experimental results showing such a reversal are discussed later.

Treatment $(b)$.-When the rapid cooling begins after the glass has been held for a short time at a 
temperature that is near the upper limit of the annealing range of the high-temperature component, and which is too low for working the glass, the organization of this component into a sort of framework that extends throughout the body of the glass will be somewhat more definite than it was after treatment (a). Nevertheless, it, as well as the low-temperature component, will be chilled. Consequently, both components will show exothermic effects when reheated for test and these effects may be more distinct than before if, as suspected, the organization of the hightemperature component has withdrawn some silica from the other component. Curve 4, figure 1 , is an example of the heating curves obtained on samples heat treated in this manner. However, this treatment does not differ sufficiently from that discussed under treatment (a) to produce a materially different density or expansion curve.

Treatment $(c)$. - If the rapid cooling from high temperatures is stopped at some temperature in but above the midpoint of the annealing range of the low-temperature component, the other component, despite its very high viscosity, will become almost completely organized and annealed if a reasonable time is allowed before the rapid cooling is resumed. Annealing of the hightemperature component at such a comparatively low temperature is possible because of the fluxing action of the more mobile low-tempearture component which, with comparative rapidity, reaches an equilibrium condition corresponding to the holding temperature. During this rapid adjustment, the low-temperature component shrinks and there is, in the initial stages of this shrinkage, a negative expansion of the glass. However, as this adjustment nears completion and consequently slows up, a slower developing positive expansion effect gains ascendency as the high-temperature component frees itself from compression as described under treatment (a).

When this treatment of the glass is completed by a rapid cooling to atmospheric temperatures, the low-temperature component is only partially annealed in the sense of being brought to equilibrium at low annealing temperatures. However, the other component should be rather thoroughly annealed. Consequently, a heating curve test will show an indication of only one exothermic effect and that will be comparatively small and near the lower limit of the annealing range of the low-temperature component. On the other hand, the indication of an endothermic effect in this curve will be especially marked in the annealing range of the high-temperature component. Curve 3 , figure 1 , is such a heating curve. ${ }^{3}$

Because of the expansion of the high-temperature component as it is released by heat treatment (c) from much of the compression imposed upon it by the other component, the density of the glass on reaching atmospheric temperatures is appreciably lower than when the cooling is rapid and continuous from high to atmospheric temperatures as in treatments (a) and (b). Thus, this release from compression accounts for the apparent minimum density obtained by certain treatments in previous investigations $[2,3]$.

An expansion curve obtained after treatment (c) will resemble, in many respects, that of a slightly annealed ordinary glass because the low-temperature component, which mainly determines the form of the curve below its softening range, has received such an annealing. Consequently, the curve will show no reduction in the expansion rate at temperatures near the beginning (lower end) of the annealing range of this component, but it will show a very rapid expansion in the range of the first endothermic effect. However, if the heating for the test is stopped sharply and held at a temperature near the upper limit of the annealing range of this component, the glass will contract somewhat at the constant temperature instead of expanding slightly for a time as a normal glass does in continuing to equilibrium. This contraction develops because the glass has been heated beyond the holding point of the previous treatment by which the high-temperature component was to a great extent freed of compression and by which a sort of equilibrium condition was established between the two components. In heating beyond this point, the more rapidly expanding low-temperature component elastically distends the comparatively rigid spatial network of the high-temperature component. In other words, the mole-

\footnotetext{
${ }^{3}$ All of the heating curves, such as curves 1 to 5 in figure 1 , which were obtained on an ordinary Pyrex glass, indicate that the endothermic effect of the high-temperature component occurs between $600^{\circ}$ and $700^{\circ} \mathrm{C}$, approximately. For a pure silica glass it occurs near $1,100^{\circ} \mathrm{C}$ and is small and not particularly definite. Presumably, this effect of the high-temperature component occurs at considerably lower temperatures and is comparatively large and definite under some conditions because the component is not composed of silica alone and also because of the solvent action of the other component at temperatures well above its annealing range.
} 
cules of the highly viscous low-temperature component being hampered by the almost rigid network of the other component cannot flow immediately into all of the excessive intermolecular spaces as they develop. Consequently, a slight overexpansion of the glass has developed when it reaches the top temperature of the expansion test described. At this temperature, the overexpansion soon disappears as the elastic network frees itself of distension and the excessive intermolecular spaces are filled through flow of the low-temperature component. This contraction effect is an exception to Marchis' [8] rule that the expansion cycle of glasses is counterclockwise.

Treatment $(d)$.- The molded object, from which the samples corresponding to curves 1 to 5 in figure 1 were taken, was large and thick compared to ordinary tubing, although it was doubtless cooled rather rapidly through the annealing range of the high-temperature component. However, because of the size of the object, the cooling rate on reaching the annealing range of the low-temperature component must have been appreciably slower than the rates to which smaller objects, such as ordinary tubing, are subjected in their production. Consequently, such a treatment should give the low-temperature component an intermediate annealing, but should leave the other component in a highly compressed condition.

The density of the glass on reaching atmospheric temperatures in a condition such as this will appreciably exceed that found after treatments (a) and (b). Density determinations made on a similar glass that had received a treatment not unlike that being discussed were presented in a previous publication [2].

The expansion curve following treatment (d) resembles that described under treatment (c), but the rapid expansion is somewhat greater. The endothermic effect of the low-temperature component is relatively definite, although decreased somewhat by the following exothermic effect of the other component. This decrease appears because the two effects tend, as usual, toward mutual obliteration. Having been chilled, the high-temperature component contributes only a small endothermic effect. Curve 2 of figure 1 represents a heating curve of this kind.

Treatment (e).-If a sample of either of the glasses yielding curves 2,4 , and 5 is retreated for a very long period at a temperature near the lowest possible effective annealing temperature for a lowtemperature component, this component will receive a very thorough annealing and will shrink considerably. The other component will remain in a chilled state and will be subjected to a very severe compression. As a result, the density at room temperature after the glass receives such a treatment will approximate the highest that the glass can attain. However, if the treatment at the low-annealing temperature is extended to a duration of some months, the density will begin to decrease very slowly. This decrease develops because the compressed high-temperature component, even at such low-annealing temperatures, is still capable of freeing itself slowly from the compression despite the extremely high viscosity of the other component.

The expansion curve of the glass after being treated as suggested under treatment (e) will be similar to those described for treatments (c) and (d), except that the rapid expansion in the temperature range of the endothermic effect of the low-temperature component will be still more pronounced. (Expansion curves of the various types mentioned are shown in later figures.) The heating curve of this glass will show a very pronounced endothermic effect for the highly annealed low-temperature component, but the endothermic effect for the high-temperature component will be small as in the case of treatment (d). Curve 1, figure 1, is the type of differential heating curve obtained after treatment (e).

\section{Second Type of Glass}

Curve 6 of figure 1 is a heating curve obtained on glass tubing marketed under the designation G702P. As this glass had presumably received no heat treatment except that of a rapid cooling after drawing, its treatment probably approximated treatment (a), but the curve more nearly resembles curve 4 obtained after treatment (b). The indications of exothermic and endothermic effects in this glass are more pronounced than in ordinary Pyrex glasses. Also, there appears to be a more definite separation between the annealing. ranges of the two components. In other words, the indicated annealing range of the low-temperature component is somewhat lower, and that of the other is somewhat higher in curve 6 than in curves 1 to 5 . The very distinct indication of an endothermic effect for the high-temperature com- 
ponent suggests that this component is unusually well organized in this glass even after a rapid cooling from high temperatures. The comparatively large effect may also mean that the composition of the high-temperature component in this glass differs materially from the composition of the corresponding component in ordinary Pyrex glasses.

The comparatively marked indications of all heat effects in curve 6 suggest that the variations in the rapid-expansion effects and in the density changes resulting from differences in treatment will also be comparatively large in G702P. As the composition of this glass was doubtless designed to produce a somewhat higher expansivity than that of ordinary Pyrex, such results are to be expected. That is, an increased expansivity in the vitreous-solid condition is usually accompanied by an increased expansivity for the glass after it definitely becomes a viscous liquid on being heated to the annealing range or higher.

\section{Expansion Effects}

\section{Typical Expansion Curves of Chilled Glasses}

Having arrived at specific conclusions relative to the expansion effects to be observed as a result of tests made after a two-component glass is heat treated according to different schedules, these conclusions will now be used as aids in interpretating a great variety of results obtained by a somewhat wider range of treatments and tests. These expansion tests were all made on tubing having an outside diameter of about $12 \mathrm{~mm}$. The approximate composition of this ordinary Pyrex tubing has been given in a previous publication [3], and this composition is not markedly different from that of the glass used in procuring the previously discussed heat effects. The method of measuring the expansions was also described in that publication. The heating rate used in the expansion tests approximated $3^{\circ} \mathrm{C} / \mathrm{min}$ and, above $450^{\circ} \mathrm{C}$, the cooling rate was not appreciably different from that of heating.

Figure 2 presents the expansion curves (both heating and cooling branches) to $600^{\circ} \mathrm{C}$ for samples from two pieces of ordinary Pyrex tubing. These samples had received no additional treatment before the tests. Consequently, their condition presumably approximated that produced by treatment (a). Curves for two samples

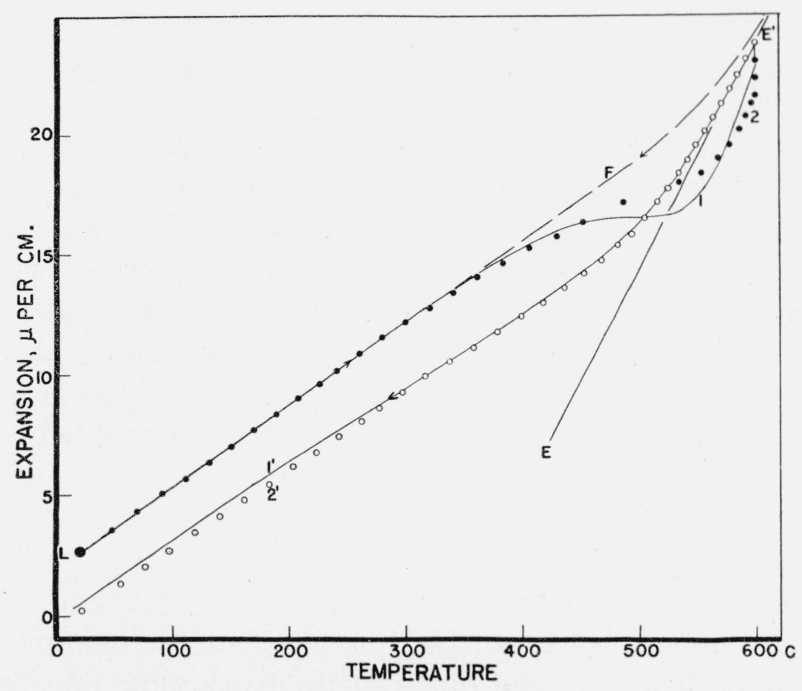

FIGURE 2. Thermal-expansion cycles of two samples of ordinary Pyrex tubing.

Curves 1 and $1^{\prime}$, unbroken lines, heating and cooling branches for sample from the glass used in tests represented by figures 3 to 8 , and 10 . Curves 2 and $2^{\prime}$, dots and circles, similar branches for sample from glass used in tests represented by figure 9 . Curve $F$, representation of contraction probably followed as tube was cooling after being drawn. $L$, The point reached by curve $F$ at $20^{\circ} \mathrm{C}$. (If the length of the sample at the end of cooling branch $2^{\prime}$ is considered to have been $1 \mathrm{~cm}$, it follows that $L=1.00025 \mathrm{~cm}$, approximately, was the initial length of the specimen). Line $E E^{\prime}$ is tangent to cooling branches at $600^{\circ} \mathrm{C}$. (For a one-component glass, this tangent usually indicates approximately the trend of the equilibrium curve.)

are presented in order to show the maximum variation observed in the heating branches of expansion curves obtained on original specimens that have been chilled in their production. Special chilling treatments of considerable severity cause a much more pronounced reduction in the rate of expansion than is exhibited by curve 1 between $375^{\circ}$ and $535^{\circ} \mathrm{C}$. Less severe chilling treatments result in curves that resemble curve 2, which is indicated by dots. In comparing curves of this nature, care must be taken to insure that the heating rates within the annealing range have been the same in the two or more tests. For instance, a somewhat higher rate of heating in procuring curve 2 could have been the cause of an appreciable part of the difference between curves 1 and 2 .

In these tests, the samples were held 1 hour at the top temperature. During this period of constant temperature, there was a small expansion as the low-temperature component approached its equilibrium condition at that temperature more closely, and also as the high-temperature component completed the freeing of itself from the compression previously imposed upon it. The 
magnitude of this compression when $600^{\circ} \mathrm{C}$ is reached in a heating test depends to a great extent on the rate of heating.

The maximum compression of the high-temperature component developed at some time before the top temperature, $600^{\circ} \mathrm{C}$, was reached in the test. This maximum compression derived from two sources. Part of it developed during the initial cooling from the drawing temperature, and it developed because of the comparatively low expansivity of the high-temperature component. Obviously, most of this part is automatically relieved by reheating to $600^{\circ} \mathrm{C}$, if no complicating conditions develop. The other part of the compression developed during the reheating, and it developed because the low-temperature component shrunk in the range of its exothermic effect; but most of this compression was also relieved before $600^{\circ} \mathrm{C}$ was reached. This relief results from the extraordinary expansion of the lowtemperature component in the range of its endothernic effect. Consequently, on reaching $600^{\circ} \mathrm{C}$ in expansion tests on chilled samples of these twocomponent glasses, very little of the compression of the high-temperature component remains except the portion that developed before $600^{\circ} \mathrm{C}$ was reached during the cooling that caused the chilled conditions. Furthermore, much of this portion will also have been dissipated before reaching such temperatures if a low heating rate is employed in the expansion test.

The decrease in length from point $\mathrm{L}$ to approximately zero (about $2 \mu / \mathrm{cm}$ ) resulting from the expansion cycle was caused by the partial annealing of the low-temperature component. Most of this annealing (decrease in equilibrium temperature) took place during the cooling from $600^{\circ}$ to $500^{\circ} \mathrm{C}$ while procuring the cooling branch. The shrinkage accompanying this annealing again compressed the high-temperature component, but to a lesser degree than that which existed prior to the test. A lower cooling rate would possibly have resulted in a smaller compression, but to what extent is uncertain because a lower rate develops more shrinkage of the low-temperature component as well as allowing more time for the other component to free itself from compression.

Curve 1, figure 3, represents the expansion cycle obtained on a sample of the G702P tubing before it received additional treatment. Consequently, the discussions presented under treat-

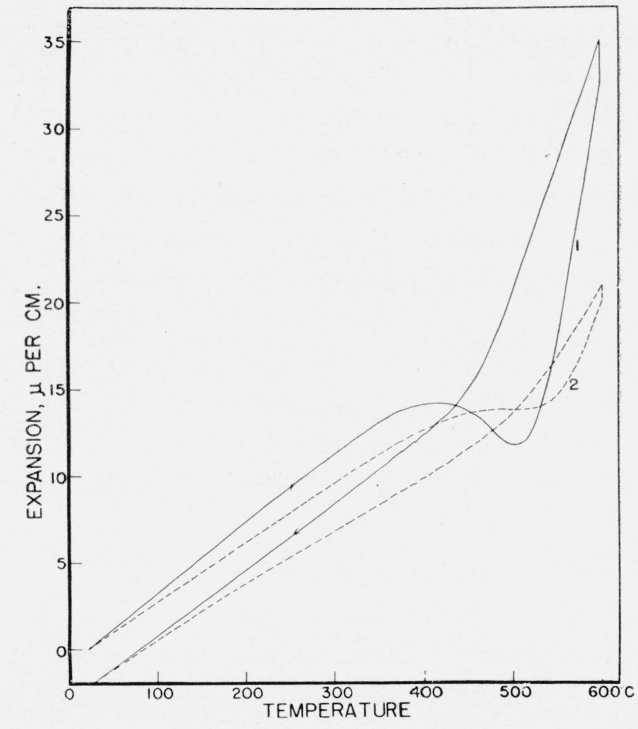

FIGURE 3. Comparison of the thermal-expansion cycles for G702P and an ordinary Pyrex glass.

Curve 1, cycle for G702P; Curve 2, reproduction of branches 1 and $1^{\prime}$, figure 2 .

ment (a) and in section II, 2 apply. As expected, the expansion effects are much more pronounced in this glass than in ordinary Pyrex. After the first expansion cycle, the resultant decrease in length per centimeter approximated that shown by Pyrex (curve 2) under the same conditions. Considering the greater expansions of G702P, this result may seem strange, but a second cycle on the same sample yielded an explanation. In this test, the heating branch coincided with the cooling branch of the first cycle until the anealing range of the low-temperature component was reached. From this point to $600^{\circ} \mathrm{C}$, the heating branch was steeper than the cooling branch of the previous cycle. Therefore, the length of the sample was about $1.75 \mu$ greater than before at the top temperature. As a result, the sample had practically regained its initial length at the end of the second cycle. This indicates that the shrinkage caused by the partial annealing of the low-temperature component was offset completely by relieving the high-temperature component of the compression imposed on it before the glass had reached $600^{\circ} \mathrm{C}$ during its initial cooling. Enough of this offset developed during the first cycle to prevent an exceptional shrinkage as compared to that obtained on ordinary Pyrex.

During the 1-hour holding period at $600^{\circ} \mathrm{C}$ in the second test, there was a slight shrinkage in- 
stead of an expansion as in the equal holding period of the previous test. This shrinkage cannot be ascribed to deformation, because the softening point of both this glass and ordinary Pyrex is about $670^{\circ} \mathrm{C}$-if that point is defined as the temperature at which the rate of collapse of the fine points supporting the sample and the top plate of the interferometer equals the rate of expansion while heating at a rate of $3^{\circ} \mathrm{C} / \mathrm{min}$. This shrinkage, resulting from a slight over-expansion developed in heating to $600^{\circ} \mathrm{C}$ for the second time, corresponds to the possible effect that was mentioned in the last paragraph under treatment (c).

Doubtless, the high-temperature component, in freeing itself from the compression that developed above $600^{\circ} \mathrm{C}$ during the cooling after the drawing of the tubing, contributed appreciably to the rapid expansion between $500^{\circ}$ and $600^{\circ} \mathrm{C}$ in the heating branch of curve 1. However, most of this very large expansion is the result of the comparatively high expansivity of the low-temperature component in its liquid state and of the superheating imposed on this component after it passes through an equilibrium condition at a temperature near that of the minimum of the curve. This expansion developed at the rate of about $0.31 \mu /(\mathrm{cm}$, deg. C), whereas the corresponding rate for ordinary Pyrex is about 0.14. These rates depend on the rate of heating and are even larger for most ordinary glasses.

The rate of contraction between $600^{\circ}$ and $500^{\circ}$ $\mathrm{C}$, as indicated by the cooling branch of curve 1 , approximates $0.15 \mu /(\mathrm{cm}$, deg $\mathrm{C})$. This rate is lower than the expansivity of the low-temperature component as a liquid because there is some undercooling (departure from the equilibrium curve), even when cooling at a rate of $3 \mathrm{deg}$. $\mathrm{C} / \mathrm{min}$, and also because of the lower expansivity of the hightemperature component. For ordinary Pyrex, the contraction rate of the cooling branch under similar conditions is about $0.08 \mu /(\mathrm{cm}$, deg. C). After considering both the apparent rates of expansion and contraction and the general appearances of the curves above $500^{\circ} \mathrm{C}$, it is estimated that the expansivities of the low-temperature components in the liquid phase are (in the above units) about 0.24 for the G702P and 0.09 for the ordinary Pyrex, provided the effect of the hightemperature component is ignored.

Compared to the above expansivities for the liquid phases of the low-temperature components, the expansivities for the glasses in the vitreous solid conditions at $100^{\circ} \mathrm{C}$ are (when expressed in the same units) about 0.039 and 0.034 for G702P and ordinary Pyrex, respectively, before the glasses receive any heat treatment. Long periods of treatment at $450^{\circ} \mathrm{C}$ reduce these expansivities at $100^{\circ} \mathrm{C}$ to about 0.035 and 0.031 , respectively.

\section{Reversal from Contraction to Expansion by Chilled Glass at Constant Annealing Tempera- tures}

In figure 4 , curves $A$ and $B$ represent the first, and curves $C$ and $D$ the second, expansion cycle on a previously untreated sample of ordinary

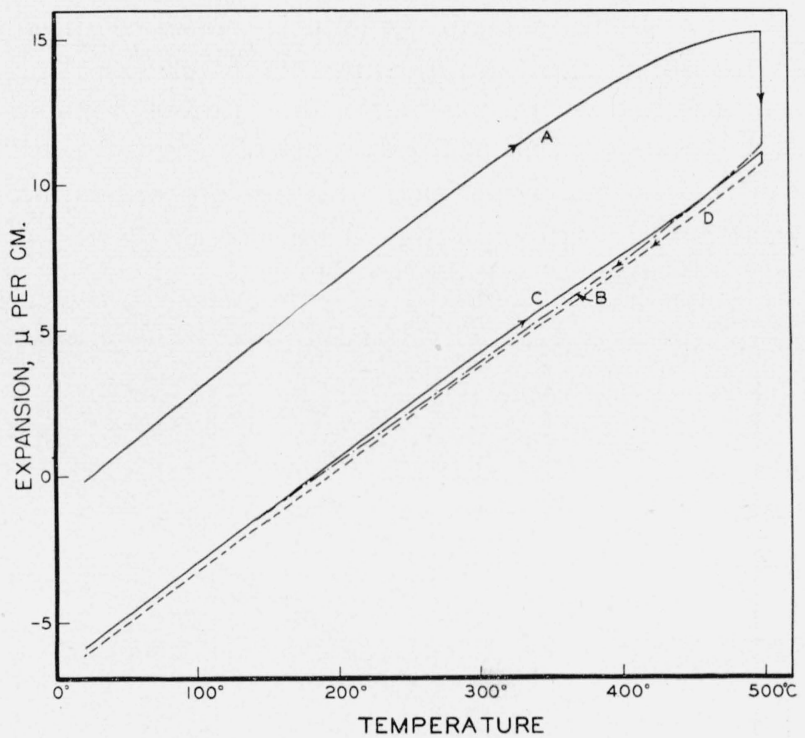

Figure 4. Thermal-expansion cycles to $500^{\circ} \mathrm{C}$.

Curves $A$ and $B$, heating and cooling branches of first cycle. Curves $C$ and $D$, same for second cycle. Holding periods for contraction at constant temperatures were 2 hours for each cycle. A reversal from contraction requires a much longer total holding period.

Pyrex tubing. In these cycles, the top temperature was $500^{\circ} \mathrm{C}$, and the holding period was 2 hours in each case. Throughout the 4 hours of treatment at this temperature, the contraction of the low-temperature component completely overshadowed any expansion caused by the other component as it freed itself from compression. According to experience gained in procuring data for the previously mentioned [2,3] curve showing the change in density with change in treating temperature, a treating period of not less than 1 day would be required before these opposed effects became balanced so that the contraction ceased. 
The two cycles shown in figure 5 were obtained under conditions like those mentioned in connection with the previous figure, except that the holding temperature was $525^{\circ} \mathrm{C}$. In this case, the 2-hour holding period of the first cycle was more than sufficient to reach a balance between the contraction and expansion of the low- and high-temperature components, respectively. Consequently, the glass began to expand at a slow rate before the end of the holding period of the first cycle. This expansion continued during the second cycle, and the cooling branch $D$ would have been brought closer to branch $A$ than to branch $B$ in the range of atmospheric temperatures if, in procuring branch $D$, the cooling rate had been increased greatly and the holding period at $525^{\circ} \mathrm{C}$ had been made as long as those required to establish an equilibrium condition at this temperature in the previously mentioned density experiments. The possibility of this change from contraction to expansion during an annealing treatment (as shown in figs. 5 and 6 ) was discussed under treatment (a), section II.

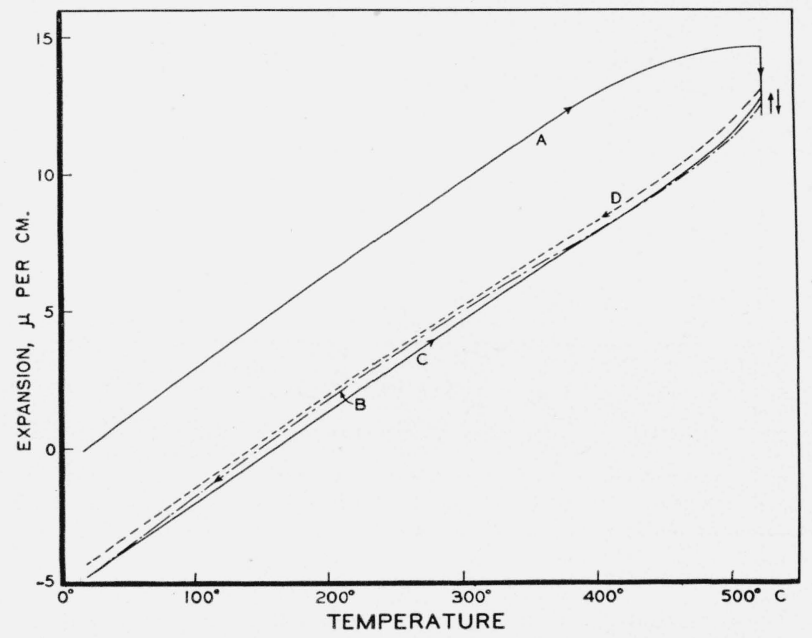

Figure 5. Thermal-expansion curves to $525^{\circ} \mathrm{C}$.

Curve designations have same significance as in figure 4. Holding periods. 2 hours for each cycle. Reversal takes place during first cycle.

When the holding temperature was raised to $550^{\circ} \mathrm{C}$ without other change in the test conditions, the results shown in figure 6 were obtained. In this case, there was a change from contraction to expansion before the first holding period of 2 hours was half over. Moreover, branch $C$ of the second cycle shows that the freeing of the high-temperature component from compression was renewed as

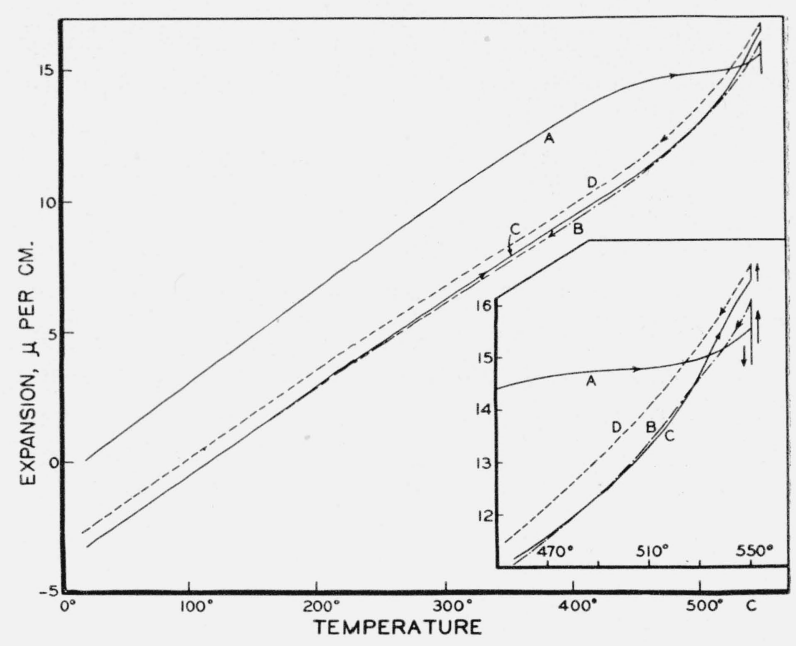

Figure 6. Thermal-expansion cycles to $550^{\circ} \mathrm{C}$.

Curve designations same as in figure 4. Holding periods, 2 hours for each cycle. Inset is an enlargement to show reversal more clearly.

the glass was heated from $530^{\circ}$ to $550^{\circ} \mathrm{C}$ and was continued throughout the second holding period at the latter temperature. In normal glasses in which there is practically no indication of this freeing effect, branch $C$ remains below branch $B$. Had the holding period of the second cycle been increased to 3 or 4 days, as in the previously mentioned density experiments, and had the cooling rate been made high enough to chill the lowtemperature component severely and thereby to prevent that part of its contraction which an approach to equilibrium at temperatures below $550^{\circ} \mathrm{C}$ causes, branch $D$ would have been above branch $A$. That is, the treatments provided by the two tests would have lengthened rather than shortened the sample tested.

The initial contraction during the first holding period at $550^{\circ} \mathrm{C}$ shows that the low-temperature component was still approaching equilibrium from a condition corresponding to a higher temperature. This contraction effect in a normal glass does not cease until branch $A$ cuts the equilibrium curve. It is estimated that an extension of branch $A$ (fig 6 ) to approximately $560^{\circ} \mathrm{C}$ would have been required before such an intersection was reached. Curves 4 and 5 of figure 1 indicate about the same temperature because the exothermic effects, attributed to the low-temperature component, end in that neighborhood. This estimate places the intersection almost $30 \mathrm{deg} \mathrm{C}$ above the intersection of curve 1 with curve $E E^{\prime}$ in figure 2. However, $E E^{\prime}$ is merely the approximate slope of the expan- 
sion and contraction curves in the neighborhood of $600^{\circ} \mathrm{C}$, which was found to be the lowest temperature at which heating and cooling curves obtained by using rates of $3 \mathrm{deg} \mathrm{C} / \mathrm{min}$ still coincided approximately. For a normal glass, this tangent usually approximates the equilibrium curve as determined by dimensional measurements. Apparently, a two-component glass has no such fairly definite equilibrium curve.

\section{Overexpansion Effects}

Raising the holding temperature to $575^{\circ} \mathrm{C}$ without any other change in the test conditions yielded the curves shown in figure 7 . In this test, the low-temperature component on the first heating (branch $A$ ) crossed its equilibrium curve near

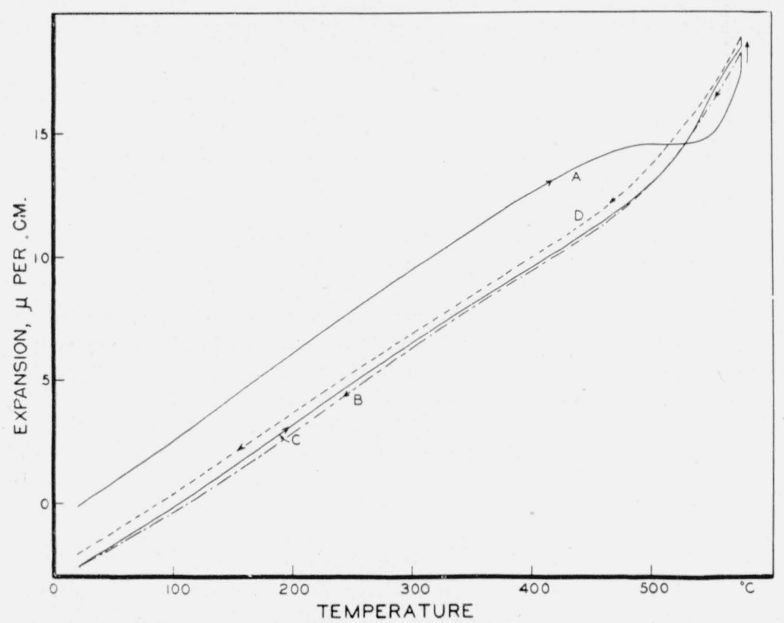

Figure 7. Thermal-expansion cycles to $575^{\circ} \mathrm{C}$.

Curve designations same as in figure 4. Holding periods, 45 minutes for each cycle. No contraction at this temperature. The practical completion of the expansion would require less than 1 day.

$560^{\circ} \mathrm{C}$ and became superheated to an undetermined degree. The degree of superheating is uncertain because, as indicated above, the location of this equilibrium curve is undetermined. On becoming superheated, the low-temperature component no longer contracts, but instead, begins to expand rapidly before $575^{\circ} \mathrm{C}$ is reached. At the same time, the increased deformability allows the high-temperature component to free itself more rapidly from compression and, thereby, to add materially to the rate of expansion. On reaching $575^{\circ} \mathrm{C}$, some superheating and compression still remained to contribute an expansion during the holding period. This delayed expansion continued even during the second holding period and had not been completed after a total holding time of 1 and $1 / 2$ hours. Had it been completed and had the cooling rate of the second cycle been very rapid, branch $D$ would have remained well above branch $A$ throughout its whole course. Completion of this expansion during the holding period of the first cycle would have caused an over expansion to take place during the second heating, and a small contraction would have resulted during the second holding period at $575^{\circ} \mathrm{C}$. As mentioned under treatment (c), a sufficiently long holding (or annealing) period at temperatures in the upper part of the annealing range of the low-temperature component results in such contraction effects on the second heating to the holding temperature.

This overexpansion effect appears in the second cycle of figure 8 , which shows the curves obtained by tests in which the holding temperature was $600^{\circ} \mathrm{C}$. The relatively high deformability of the low-temperature component at this holding temperature allowed the delayed expansion to be practically completed during the first holding period. This completion sets the conditions for an overexpansion during the succeeding cycle. As long as devitrification does not develop, the point approached by the expansion and contraction of the first and second holding periods, respectively, is a point on the equilibrium curve of the glass as a whole.

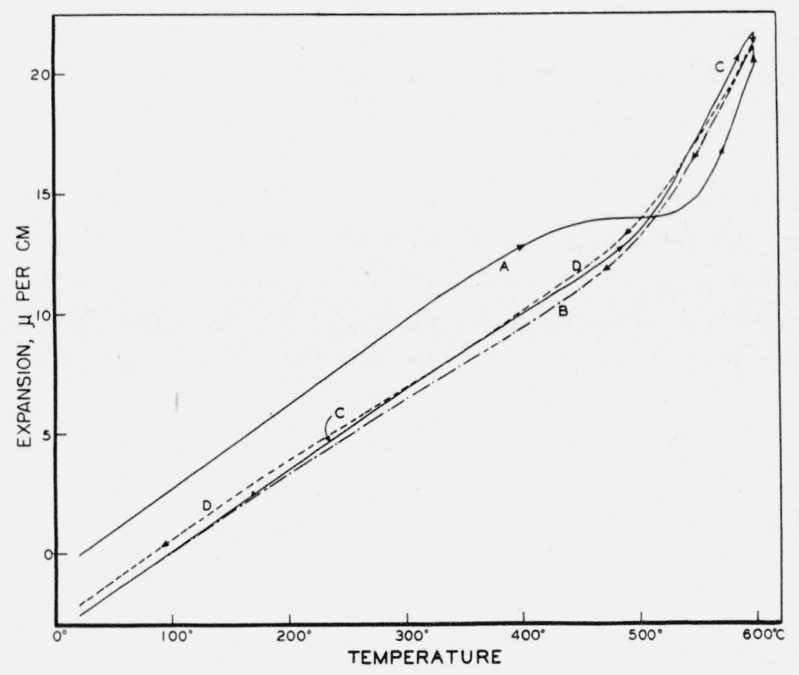

Figure 8. Thermal-expansion cycles to $600^{\circ} \mathrm{C}$.

Curve designations same as in figure 4. The delayed expansion was practically completed during the holding period of 45 minutes in the first cycle. The overexpansion developed during the second heating caused a contraction during an equal holding period of second cycle. 
It is only at holding temperatures in the range from about $575^{\circ}$ to $650^{\circ} \mathrm{C}$ that overexpansion effects are observed, and they do not appear at such temperatures unless the high-temperature component has first been freed from compression at temperatures well below the proposed holding temperature. Also, these effects are never very marked unless the low-temperature component has first been brought to equilibrium at temperatures below $575^{\circ} \mathrm{C}$. However, reducing the equilibrium temperature below $500^{\circ} \mathrm{C}$ will seldom result in such an effect unless the hightemperature component has been freed from compression by treatment at a higher temperature. The overexpansion effect is not observed at holding temperatures below $575^{\circ} \mathrm{C}$ in this glass, because the rapid expansion effect does not begin, even in a well annealed sample (see curve $A$, fig. 11), until temperatures near $550^{\circ} \mathrm{C}$ are reached. It is not observed above $650^{\circ} \mathrm{C}$ because the deformability has become so great in that range that all delayed expansions and contractions are practically completed before that temperature is reached.

The samples used in the expansion tests so far discussed were not in the condition required to develop an overexpansion on the first heating because none of them had received any treatment except the rapid cooling following the drawing of the tubing. Moreover, the holding temperatures were in the range of possible overexpansion in only three cases (figs. 2, 7, and 8). The expansion curves presented in figure 9 show some of the treatments (all followed by rapid cooling) that result in delayed expansions, on the one hand, and in overexpansions, on the other, when the samples receiving these treatments are subjected to a first expansion cycle with $600^{\circ} \mathrm{C}$ as the holding temperature. From the curves and the data presented in the legend it will be noted that the treatments resulting in delayed expansions (curves $0,1,2,8$, 9 , and 10 ) at the holding temperature fall into two categories: (1) those that allowed neither the freeing of the high-temperature nor the annealing of the low-temperature component (because the treating temperatures were too high), and (2) those that allowed a rather thorough annealing of the low-temperature component but no freeing of the other from compression (because the treating temperatures were too low). The treatments resulting in overexpansions (curves 3 to 7 ) were all

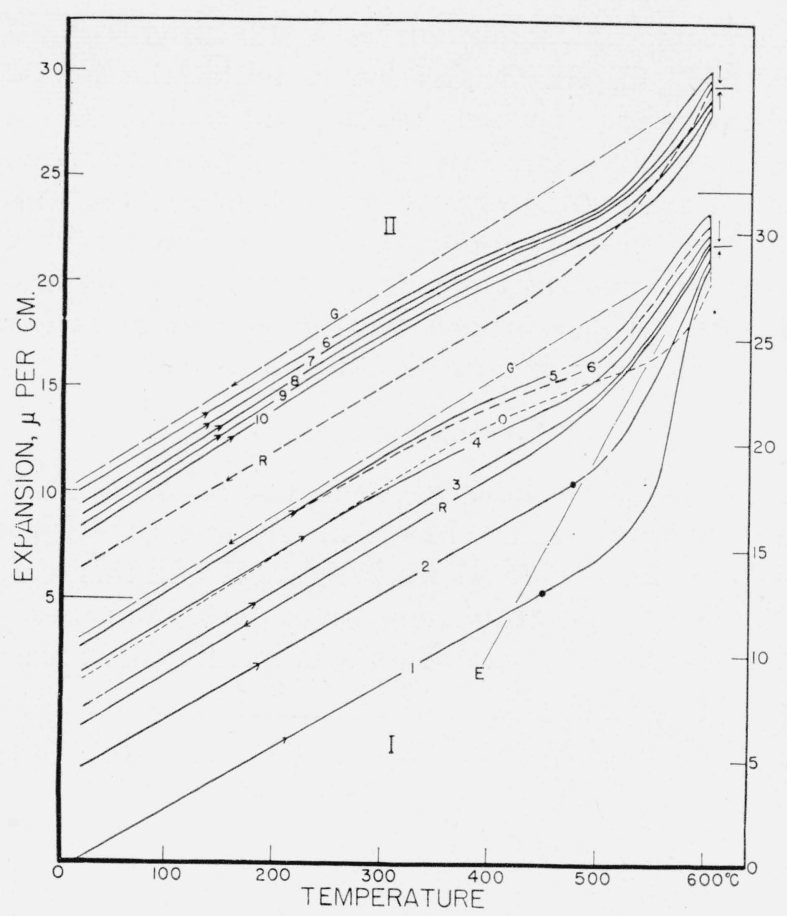

Figure 9. Expansion or contractions shown at $600^{\circ} \mathrm{C}$ by $\mathrm{C}$ number or differently treated samples.

Curves divided into two assemblages (I and II) to avoid interference. Numbered curves are heating branches. Curve $R$, cooling branch common to all cycles in both assemblages. Curve $G$, (both assemblages) estimated course of common cooling branch from $600^{\circ} \mathrm{C}$ if cooling rate had been very high after equilibrium had been establshed at that temperature. Curve $E E^{\prime}$ reproduced from figure 2. Holding periods, 45 minutes. According to the results, the samples tested fall into two fairly distinct groups. Group 1, samples showing delayed expansions on reaching $600^{\circ} \mathrm{C}$, curves $0,1,2,8,9$, and 10 . Treatments of corresponding samples: 0 , untreated (see curve 2, fig. 2); 1 , treated 2 months at $450^{\circ} \mathrm{C} ; 2,2$ months at $475^{\circ} \mathrm{C} ; 8,2$ hours at $700^{\circ} \mathrm{C} ; 9,1$ hour at $725^{\circ} \mathrm{C}$; and 10,1 hour at $750^{\circ} \mathrm{C}$. Not included in figure: Sample treated 6 hours at $675^{\circ} \mathrm{C}$, curve between 7 and 8 . Group 2, samples showing overexpansion and resultant contraction on reaching $600^{\circ} \mathrm{C}$, curves 3 to 7 , inclusive. Treatments of corresponding samples: 3,2 months at $500^{\circ} \mathrm{C}$; 4,1 month at $525^{\circ} \mathrm{C} ; 5,9$ days at $550^{\circ} \mathrm{C} ; 6,7$ days at $575^{\circ} \mathrm{C} ; 7,3$ days at $625^{\circ}$ C. Not included in figure: Sample treated 28 hours at $650^{\circ} \mathrm{C}$, curve between 7 and 8; also one treated 3 days at $690^{\circ} \mathrm{C}$; curve between 6 and 7 . All above treatments followed by rapid cooling.

intermediate, as the treating temperatures ranged from $500^{\circ}$ to $625^{\circ} \mathrm{C}$. The maximum effects resulted from the treatments at $550^{\circ}$ and $575^{\circ} \mathrm{C}$ (curves 5 and 6 ) as should be expected from the previous discussion. In all of these tests, the annealing caused by the heating required to obtain an expansion curve has an appreciable effect. Had this not been true, it is improbable that the treatment at $625^{\circ} \mathrm{C}$ (curve 7) would have resulted in an overexpansion effect.

Figure 10 presents examples of the clockwise cycles mentioned under treatment (c) in section II. As in the regular tests, the heating and cooling rates for these short or secondary cycles were about 


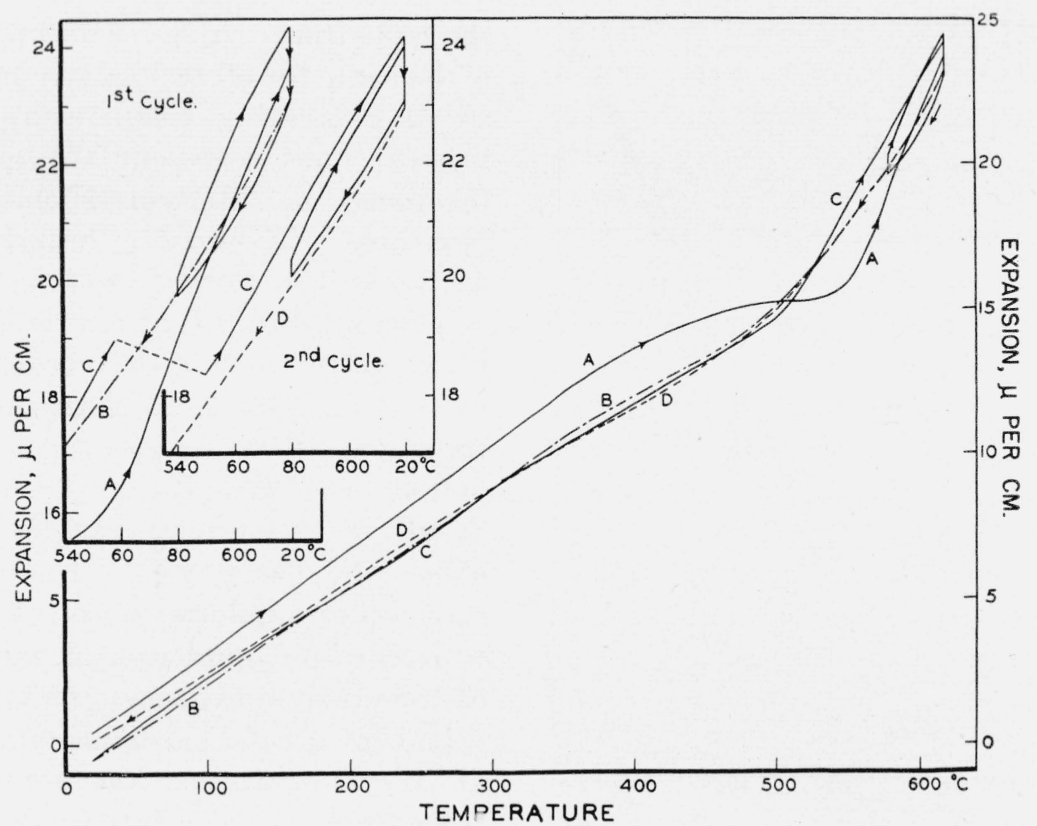

FIGURE 10. Clockwise expansion and contraction effects between $580^{\circ}$ and $620^{\circ} \mathrm{C}$.

As insets indicate, one minor cycle was interposed between branches $A$ and $B$ of the first major cycle and another between branches $C$ and $D$ of the second major cycle, although the second minor cycle is omitted from the primary graph. In normal glasses, minor cycles within the annealing range are always counterclockwise.

$3^{\circ} \mathrm{C} / \mathrm{min}$, although control of the rates is rather difficult when the cycles are so short. The holding periods at the end temperatures $\left(580^{\circ}\right.$ and $620^{\circ} \mathrm{C}$ ) of these cycles were about $45 \mathrm{~min}$, although both longer and shorter periods were sometimes used. At the lower end of the cycle this period is too short to complete all of the molecular readjustments and attendant expansion required to establish equilibrium at that temperature. However, at the upper temperature the period of 45 min appeared to be long enough to establish equilibrium. Apparently, these clockwise cycles can be repeated any number of times without any significant change in their form except some changes that can be ascribed to a lack of perfect control of the heating and cooling rates. Also, repeating the cycles causes no appreciable change in the length of the sample if its length is always measured at some temperature near $600^{\circ} \mathrm{C}$ where equilibrium can be easily established before the measurement is made.

\section{Expansion of Annealed Glass at Constant Annealing Temperatures}

As shown in previous publications [2,3], the highest density obtained for an ordinary Pyrex glass was reached when it was treated several weeks at $450^{\circ} \mathrm{C}$ after it had been chilled from a high temperature. However, a slight decrease from the maximum density was noted when the treatment was increased to several months at $450^{\circ} \mathrm{C}$. This decrease suggests that the reversal from contraction to expansion (as shown in figs. 5 and 6 ) also takes place at this low annealing temperature whenever the treatments are extended sufficiently. Any normal glass, after it has been brought to a high density by being reduced to equilibrium at a very low annealing temperature, expands whenever it is retreated at a higher temperature. This expansion continues until the equilibrium curve is again reached, and the rate of expansion depends on the mobility of the glass and the extent of the departure from equilibrium. Two-component glasses also expand under such conditions, except in those cases in which an overexpansion has been developed.

Figure 11 is presented to show this expansion and the change in rate of expansion when an annealed ordinary Pyrex glass is held at different temperatures. The samples used in this test were treated at $450^{\circ} \mathrm{C}$ until the maximum density for that temperature was approximated. However the preceding chilling treatment of these samples was not that which followed the drawing of the 


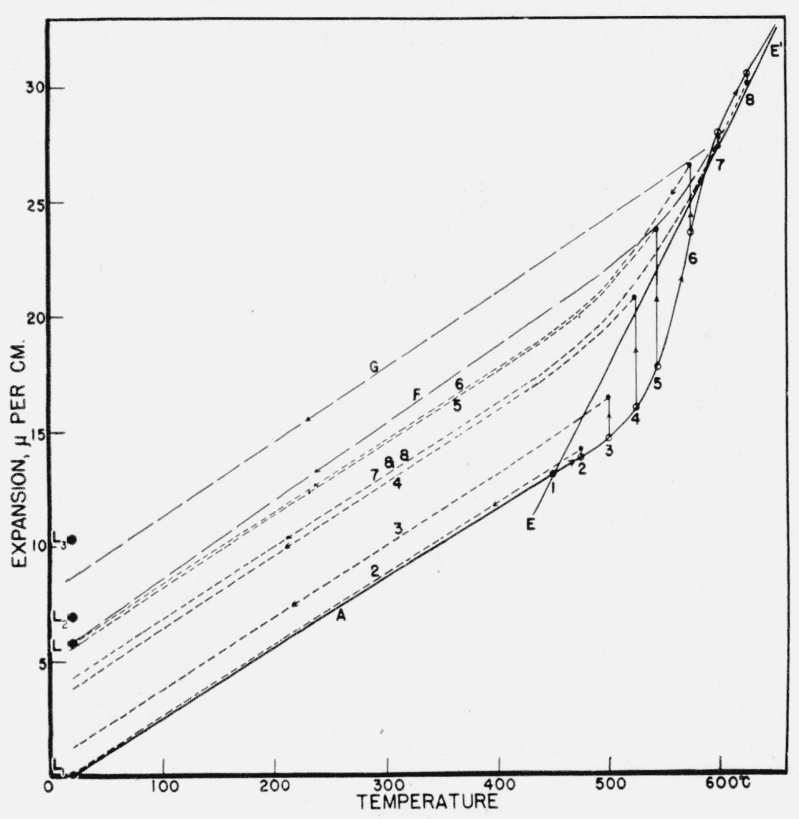

Figure 11. Expansions of an ordinary Pyrex tubing at various temperatures after pretreatment described below.

The pretreatment consisted of a very rapid cooling from $675^{\circ} \mathrm{C}$ followed by an annealing of 74 days at $450^{\circ} \mathrm{C}$. Curve $A$ represents the heating branches of the expansion cycles for all samples. The vertical lines at the holding temperatures, as designated by the sample numbers, represent the delayed expansions (or contractions) during the holding periods. The holding temperatures were $450^{\circ}, 475^{\circ}, 500^{\circ}, 525^{\circ}, 544^{\circ}, 575^{\circ}, 600^{\circ}$, and $625^{\circ} \mathrm{C}$, and the holding periods were 6 hours at temperatures 1 to 6,5 hours at temperature 7 , and 15 minutes at temperature 8 . The broken curves numbered for the samples are the cooling branches. Curve $G$ is the probable trend of the cooling branch for samples 4,5 , and 6 if they had been annealed until the completion of their delayed expansion and cooled very rapidly. Curves $F$ and $E E^{\prime}$ reproduced from figure 2 after an arbitrary and immaterial shift in their ordinates. Significance of points $L, L_{1}$, and $L_{2}$, and $L_{3}$ discussed in text.

tubing, as they had all been used in some of the tests previously described. To bring them to a uniform chilled condition prior to the final prolonged annealing treatment at $450^{\circ} \mathrm{C}$, they were heated for 6 hours at $675^{\circ} \mathrm{C}$. This temperature is near the upper limit of the range of intermediate treating temperatures from which chilling treatments were found to set up conditions that are conducive to overexpansion effects even if such treatments are followed by no other annealing than that imposed by the heating necessary to the expansion test. In view of the treatments received during the previous tests and the long annealing treatment which followed the chilling treatment from $675^{\circ} \mathrm{C}$, the slight over-expansion effects shown at the holding temperatures $600^{\circ}$ and $625^{\circ} \mathrm{C}$ in figure 11 do not seem unreasonable. (See fig. 9 also.) Curve $A$, from the beginning to point 1 , is the common heating branch for all of the tests from 1 to 8 . From point 1 to point 2, it is the same for all tests above number 1 , and so on as each treating temperature is reached. The vertical lines represent the expansions (or contractions) at the corresponding treating temperatures. The cooling branches are represented by the broken curves 2 to 8 .

The expansions that developed during a holding period of 6 hours at the various holding temperatures from $450^{\circ}$ to $575^{\circ} \mathrm{C}$ show graphically how the rates of expansion vary. Had the holding periods been extended sufficiently, the expansions at all of these temperatures would have risen above the curve $E E^{\prime}$. In fact, experience has shown that a holding period of 6 hours is sufficient to cause the completion of only about two-thirds of the possible expansion even at $575^{\circ} \mathrm{C}$. Curve $G$ and the point $L_{3}$ also indicate that the expansion at this temperature was not completed. Curve $G$ is not experimental but was drawn on the assumption that the slope of a cooling curve resulting from a very rapid cooling would have been, throughout the length of the curve, practically the same as the slope of the actual cooling branch in the neighborhood of $200^{\circ} \mathrm{C}$. According to the previously mentioned investigations $[2,3]$ of density changes, $L_{3}-L_{1}$ is the increase in length that should occur if the expansion at $575^{\circ} \mathrm{C}$ had been completed. Apparently, completion of the expansion in test 6 would have caused curve $G$ to pass very close to $L_{3}$.

From the same results [3] on density changes, $L_{2}-L_{1}$ represents the expansion that should occur at $500^{\circ} \mathrm{C}$ when the holding period is made sufficiently long. Apparently, the expansion at this temperature (curve 3) was about one-fourth completed in 6 hours. Excepting an immaterial shift in their ordinates, point $L$ and curves $F$ and $E E^{\prime}$ were introduced into figure 11 directly from figure 2. Consequently, $L-L_{1}$ should represent the contraction in length caused by the preparatory annealing at $450^{\circ} \mathrm{C}$ after the chilling from $675^{\circ} \mathrm{C}$. However, this change in length was also computed from the previously mentioned results on density changes. It is obvious that $L_{1}$ was arbitrarily made to coincide with the origin of curve $A$. Consequently, when considered as representing a length, $L_{1}$ must be assigned the magnitude of 1 $\mathrm{cm}$ because the data for the expansion curves were reduced to expansions per centimeter of the initial 
length of the samples. The ordinates of figure 2 represent the expansions per centimeter of the sample following the test. These differences, in the method of computation and in the conditions of the samples assumed to have unit length, account for the difference in the ordinates of point $L$ and of the curves $F$ and $E E^{\prime}$ as shown in figures 2 and 11.

\section{Expansion Effects in Second Type of Glass}

Figures 12, 13, and 14 represent some of the expansion data procured on samples of the glass G702P. These results were obtained under the

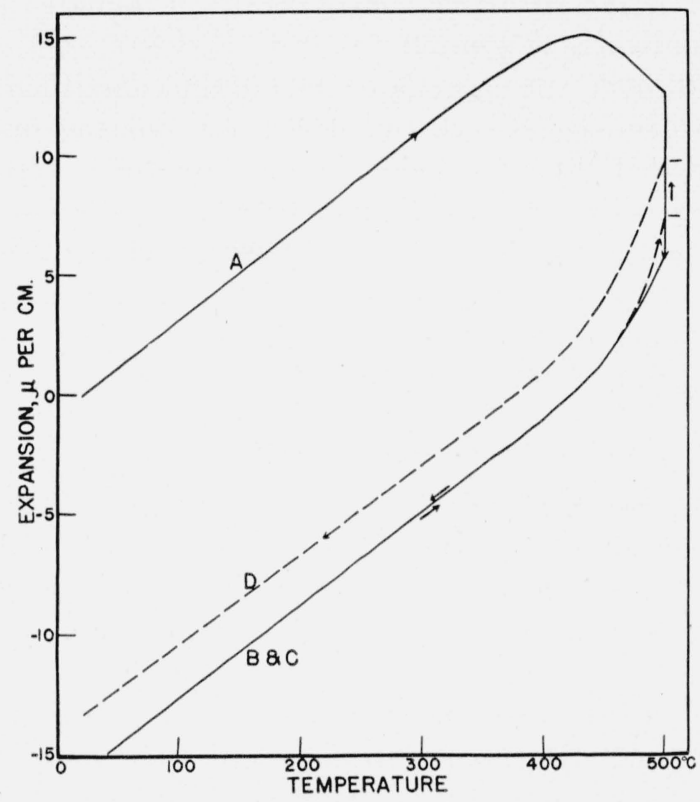

Figure 12. Thermal-expansion cycles of Gr02P glass to $500^{\circ} \mathrm{C}$.

Curve designations same as in figure 4. No pretreatment. Holding periods 2 hours for each cycle. Compare these curves with those in figure 5 for an ordinary Pyrex glass.

conditions that applied when the expansions shown in figures 4, 5, and 6 were procured on samples of ordinary Pyrex. However, it will be noted that these curves for G702P correspond more closely to those shown in figures 5 to 7 . Consequently, it appears that the annealing range of the lowtemperature component of the $\mathrm{G} 702 \mathrm{P}$ glass is about $25 \mathrm{deg}$. C lower than that of the same component in ordinary Pyrex glass. That this difference would be found was evident from the curves in figures 1 and 3 .

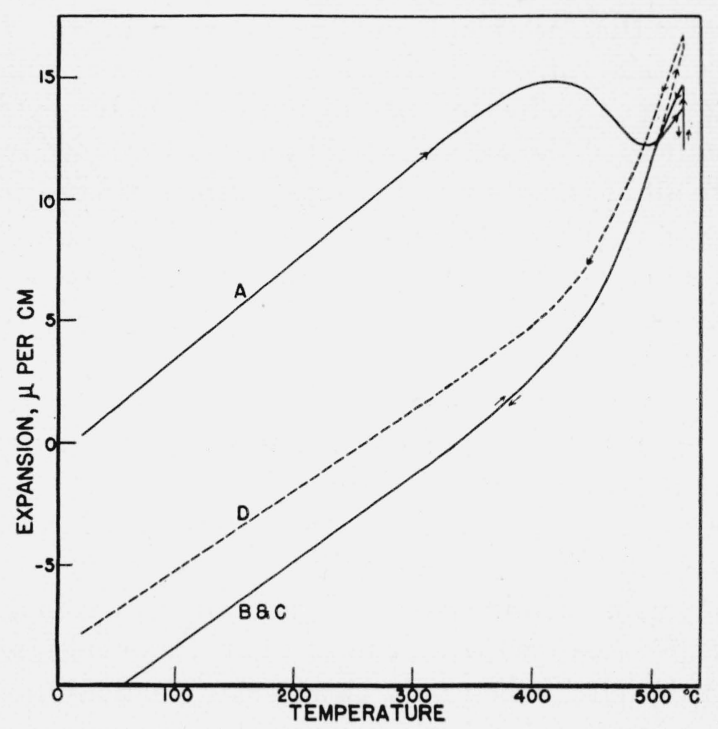

FIguRE 13. Thermal-expansion cycles of Gro2P glass to $525^{\circ} \mathrm{C}$.

Curve designations, pretreatment, and holding periods same as in figure 12. Compare these curves with those for an ordinary Pyrex glass in figure 6 .

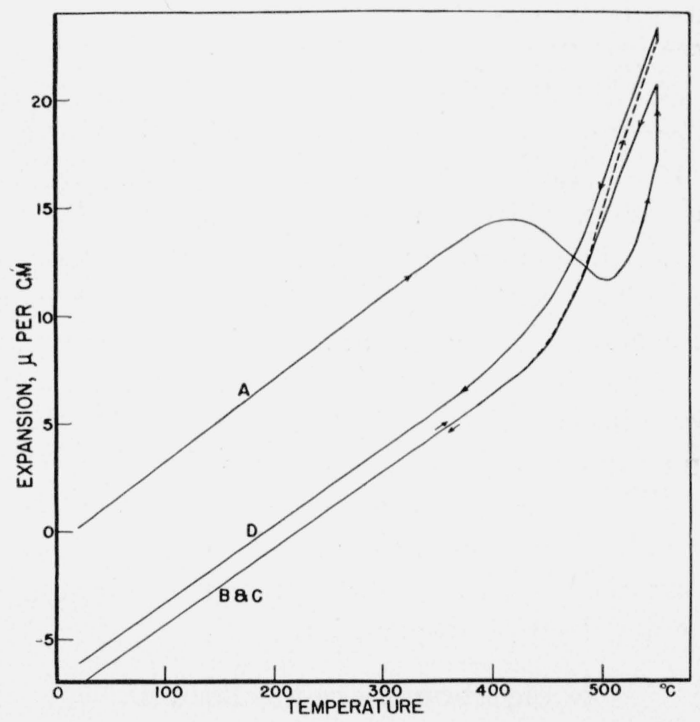

FIGURE 14. Thermal-expansion cycles of Gr02P glass to $550^{\circ} \mathrm{C}$.

Curve designations, pretreatment, and holding periods same as in figure 12. Compare these curves with those for an ordinary Pyrex glass in figure 7 .

\section{Discussion}

1. Precision of the Data and the Adequacy of Their Representation by the Curves Presented

In procuring the data for the curves showing heat effects and for those showing expansions, observations were taken at intervals seldom 
greater than $10 \mathrm{deg}$. C change in temperature. In the critical ranges, the intervals were often as small as $2 \mathrm{deg}$. C. In the case of figure 1, trebling the thickness of the curves would have covered practically all of the observed points. Repetition of the tests always showed some variation in the results, but most of this variation was directly attributable to the difficulty of exactly duplicating the rate of heating.

The same difficulty was encountered in determining expansions (or contractions) in the critical ranges where any variation in elapse of time affects the results. However, the uncertainties caused by inadvertent failure to duplicate the heating and cooling rates are generally insignificant in those cases where no more than two cycles are considered. When only two cycles, such as those in figures 4 to 8 , were procured, the two tests were made without removing the sample from the furnace and the approximate duplication of test procedure was accomplished with the least difficulty. Furthermore, the matching of several curves procured on a number of different samples and by a series of tests that required several weeks for its completion was not required as in figures 9 and 11 . The change caused by a small and unsuspected variation in heating rate within the critical range could cause a change in the order of some of the curves shown in figure 9. Excepting the lower half of the cooling branches, the expansion curves as drawn usually represent the observed points almost as well as the curves in figure 1 . Even in the cooling branches, the worst deviations from the curves as drawn were roughly $\pm 0.5 \mu$. Although about one-half of the observed points are omitted, curves 2 and $2^{\prime}$ present a fair sample of the usual set of observations.

\section{Significance of the Results}

It is believed that the expansion data presented here fully support the idea that the glasses in question are two-component glasses. Originally, this idea was based almost entirely on the peculiarities of the exothermic and endothermic heat effects that they showed when heated. As a result of this attempt to coordinate the peculiarities of the expansion effects of these glasses, it now appears that the expansion data present a rather clear picture of the manner in which the components of these glasses react upon each other during hea ting, cooling, and annealing procedures. There seems to be no indication that the components are immiscible. It seems, rather, that they are mutually bound in a rather close association, and that the glasses behave as if made up of two components because one constituent is present in such an excess that some, but not all of it, is sufficient to form a continuous spatial network that extends throughout the whole body of the glass. If the abundant constituent, with some aid from the other constituents, forms a sufficiently dense network, it appears that this network alone takes on the character of an overdistended vitreous solid, if the presence of the other component that is made up of that part of the constituents not included in the network, is ignored.

However, the unincluded part of the constituents also forms a network that has the properties of a distended vitreous solid. Such a picture of the constitution of two-component glasses does not require the concept of immiscibility, even though the chief constituent of the high-temperature component can be reduced to the crystalline phase by suitable heat treatments $[4,9]$.

\section{Summary}

The thermal expansion data presented above appear to confirm the previously expressed belief that some borosilicate glasses that contain a high percentage of silica are essentially two-component glasses.

One of these components becomes a practically rigid and continuous framework that extends throughout the body of the glass before $600^{\circ} \mathrm{C}$ is reached on cooling.

This high-temperature component is interlaced by the other component that is still so inelastically deformable at $450^{\circ} \mathrm{C}$ that its state above $500^{\circ} \mathrm{C}$ is definitely that of a liquid glass.

The expansivity of the low-temperature component is so much higher than that of the other that the latter suffers appreciable elastic compression whenever the glass is cooled and, under rapid cooling, this compression begins at rather high temperatures because even the low-temperature component acts as a solid when cooled rapidly.

Because of the additional contraction of the lowtemperature component whenever it is annealed, the extraordinary compression of the high-temperature component is greatly accentuated by 
annealing treatments at temperatures below $500^{\circ} \mathrm{C}$.

Annealing treatments at temperatures between $500^{\circ}$ and $600^{\circ} \mathrm{C}$ ultimately allow the high-temperature component to free itself from the extraordinary compression because such temperatures so reduce the viscosity of the low-temperature component that this component flows under the pressure exerted by the compressed component.

Normalizing the compression of the high-temperature component causes the glass as a whole to expand to such a degree that its specific volume after a thorough annealing at $550^{\circ} \mathrm{C}$ is greater than after a long annealing treatment at $450^{\circ} \mathrm{C}$ and is also greater than after a thorough annealing. at $600^{\circ} \mathrm{C}$ if the latter treatment is followed by a rapid cooling to the standard temperature for density determination.

The mechanical processes (the building up of, and the relaxation of, elastic molecular strains) between the two components also cause a number of more-or-less minor effects that are discussed in some detail.

\section{References}

[1] A. Q. Tool and C. G. Eichlin, J. Am. Ceramic Soc. 8, 1 (1925).

[2] A. Q. Tool and E. E. Hill, Trans. Soc. Glass Tech. 9, 185 (1925).

[3] A. Q. Tool and J. B. Saunders, BS J. Research 11, 799 (1933) RP626.

[4] A. Q. Tool and H. Insley, J. Research NBS 21, 743 (1938) RP1152.

[5] A. Q. Tool, E. L. Peffer, and J. B. Saunders, Toronto Meeting of Am. Ceramic Soc. (Feb. 19, 1930).

[6] A. Q. Tool, J. Research NBS 37, 73 (1946) RP1730.

[7] A. Q. Tool and C. G. Eichlin, Am. Ceramic Soc. 14, 276 (1931).

[8] L. Marchis, Les modifitions permanents du verre et les deplacement du Zero des thermometres (A. Hermann, Paris, 1898).

[9] A. Q. Tool and J. B. Saunders, J. Research NBS 21, 773 (1938) RP1153.

Washington, June 13, 1947. 